\title{
Model Guided Discovery Learning Berorientasi Pembelajaran Abad 21 Bermuatan Tri Kaya Parisudha
}

\author{
I Made Ari Winangun1*, I Komang Wahyu Wiguna ${ }^{2}$, Made Adi Nugraha \\ Tristaningrat ${ }^{3}$
}

1,2,3 PGSD, STAHN Mpu Kuturan,, Singaraja, Indonesia

\section{ART ICLE INF O}

Article history:

Received October 01, 2021

Revised October 03, 2021

Accepted November 30, 2021

Available online December 25, 2021

Kata Kunci:

Pembelajaran abad 21, Guided Discovery, Tri Kaya Parisudha

Keywords:

21st century learning, guided discovery, Tri Kaya Parisudha

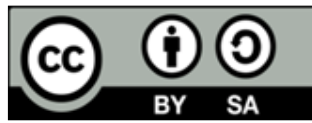

This is an open access article under the CC BY-SA license.

Copyright (C) 2021 by Author. Published by Universitas Pendidikan Ganesha.

\begin{abstract}
A B S T R A K
Pihak guru tidak dapat memastikan seluruh siswa mampu belajar daring dengan baik atau dengan kata lain kualitas belajar daring tidak dapat berjalan seoptimal pembelajaran tatap muka. Tujuan penelitian ini yaitu mengembangkan model guided discovery berorientasi pembelajaran Abad 21 bermuatan Tri Kaya Parisudha. Penelitian ini merupakan penelitian pengembangan desain dan produk (Design and Development) dengan menggunakan Model ADDIE (Analysis, Design, Development, Implementation, Evaluation). Subjek pada penelitian ini terdiri atas 2 orang ahli, 5 orang mahasiswa, dan 5 orang guru sekolah dasar. Metode yang digunakan untuk mengumpulkan data yaitu observasi, wawancara, dan kuesioner. Instrumen yang diguankan untuk mengumpulkan data yaitu kuesioner. Teknik yang digunakan untuk menganalisis data yaitu deskriptif kualitatif dan kuantitatif. Hasil penelitian yaitu model guided discovery berorientasi pembelajaran abad 21 bermuatan Tri Kaya Parisudha secara empiris telah menunjukkan validitasnya baik berdasarkan hasil ahli bahasa, ahli konten, respon mahasiswa, maupun respon guru SD yang memberikan penilaian pada kategori sangat baik. Dapat disimpulkan bahwa model guided discovery berorientasi pembelajaran abad 21 bermuatan Tri Kaya Parisudha layak diterapkan dalam pembelajaran. Implikasi penelitian ini yaitu model guided discovery berorientasi pembelajaran abad 21 bermuatan Tri Kaya Parisudha dapat membangun karakter siswa.
\end{abstract}

\section{A B S T R A C T}

The teacher cannot ensure that all students can learn to be brave, or in other words, the quality of learning to be brave cannot run as optimally as face-to-face learning. The purpose of this study is to develop a 21st Century learning-directed discovery model containing Tri Kaya Parisudha. This research is a design and product development research (Design and Development) using the ADDIE Model (Analysis, Design, Development, Implementation, Evaluation). The subjects in this study consisted of 2 experts, 5 students, and 5 elementary school teachers. The methods used to collect data are observation, interviews, and questionnaires. The instrument used to collect data is a questionnaire. The technique used to analyze the information is descriptive qualitative, and quantitative. The study results, namely the guided discovery model of 21st-century learning that is empirically charged, have shown its validity based on the results of linguists, content experts, student responses, and the responses of elementary school teachers who assessed the excellent category. It can be said that the guided discovery model of 21st-century learning containing Tri Kaya Parisudha is feasible to be applied in education. This research implies that the recommended discovery model of 21 st century learning with Tri Kaya Parisudha can build students' character.

\section{PENDAHULUAN}

Pendidikan merupakan bagian penting yang mencerminkan kemajuan suatu bangsa (Amin et al., 2021; Plenty et al., 2021). Oleh sebab itu, setiap bangsa berupaya mengoptimalkan pelaksanaan pendidikan sehingga menghasilkan sumber daya manusia yang kompetitif dan unggul (Muflih et al., 2021; Prasetyo et al., 2020; Tajvidi et al., 2014). Upaya pertama dalam pelaksanaan pendidikan adalah menetapkan tujuan pendidikan nasional. Adapaun tujuan pendidikan nasional tersebut adalah 
berkembangnya potensi peserta didik agar menjadi manusia yang beriman dan bertakwa kepada Tuhan Yang Maha Esa, berakhlak mulia, sehat, berilmu, cakap kreatif, mandiri, dan menjadi warga negara yang demokratis, serta bertanggung jawab (Arum \& Yuanta, 2019; Hidayat \& Sariningsih, 2018; Sujana, 2019). Pelaksanaan pendidikan sesuai tujuan pendidikan nasional di Indonesia diimplementasikan dalam tiga jenjang pendidikan, yaitu sekolah dasar, sekolah menengah, dan pendidikan tinggi (Breinholt \& Holm, 2020; Mitchell et al., 2017; Troussas et al., 2020). Sekolah dasar merupakan jenjang awal seseorang atau individu dalam mengembangkan kemampuan dan potensinya (Alshammari, 2020; Desyandri et al., 2019; Royanto, 2012). Pada jenjang ini, proses pembelajaran dilaksanakan menyesuaikan dengan perkembangan kognitif anak yakni pada tahap operasional konkret (Partovi \& Razavi, 2019; Pratama et al., 2021). Tahap ini, anak sudah mampu menggunakan logika atau opreasi tetapi dengan bantuan objek fisik. Tanpa objek fisik tersebut, anak sering mengalami kesulitan saat menyelesaikan tugas-tugas belajarnya terutama yang berkaitan dengan logika (Fisnani et al., 2020; Huang et al., 2020). Oleh karena itu, proses pembelajaran khususnya jenjang sekolah dasar mengalami perubahan yang mendasar. Pada kurikulum sebelumnya pembelajaran di SD bersifat parsial dan terbagi menjadi beberapa mata pelajaran, sedangkan saat ini dalam Kurikulum 2013 pembelajaran di SD bersifat kontekstual dan terintegrasi dalam suatu bentuk pembelajaran tematik untuk menstimulasi perkembangan kognitif anak (Arum \& Yuanta, 2019; Baka et al., 2018; Pambudi et al., 2019).

Implementasi pembelajaran tematik, khususnya pada situasi pandemi Covid-19 mengalami berbagai kendala baik dari pihak sekolah khususnya guru (Hutauruk \& Sidabutar, 2020; Rigianti, 2020). Berdasarkan hasil wawancara pada beberapa guru SD di Kecamatan Buleleng, menunjukkan bahwa pihak guru tidak dapat memastikan seluruh siswa mampu belajar daring dengan baik atau dengan kata lain kualitas belajar daring tidak dapat berjalan seoptimal pembelajaran tatap muka. Begitu pula saat pelaksanaan penilaian harian, guru tidak dapat mengontrol secara penuh upaya yang dilaksanakan siswa untuk memperoleh hasil tes yang optimal. Temuan penelitian sebelumnya kesulitan dalam menciptakan pembelajaran online yang sesuai dengan karakteristik siswa (Mufaziah \& Fauziah, 2020; Muflih et al., 2021; Mustakim, 2020). Hal inilah yang menjadi dasar diperlukannya upaya pelaksanaan pembelajaran inovatif yang mampu memberikan pendampingan siswa dalam belajar dan penanaman nilai atau norma untuk membangun karakter pada siswa (Simatupang et al., 2020; Soyadı \& Birgili, 2015; Suwana et al., 2013). Model pembelajaran kreatif dan inovatif dapat digunakan oleh guru berorientasi pembelajaran abad 21. Pembelajaran abad 21 merupakan perubahan pembelajaran yang pada awalnya teacher centered menjadi student centered dengan menekankan pada empat jenis keterampilan, yaitu critical thinking, communication, collaboration, dan creativity (Andrian \& Rusman, 2019; Azrai et al., 2016; Lubis, 2018). Salah satu model pembelajaran yang dapat mengembangkan keterampilan dalam pembelajaran abad 21 dan mampu memfasilitasi proses pembelajaran siswa SD sesuai perkembangan kognitifnya, yaitu model pembelajaran guided discovery (Alatas \& Sakina, 2019; Sunismi, 2015; Udo, 2011). Model pembelajaran guided discovery adalah model pembelajaran dengan desain instruksional konstruktivis yang memadukan konsep pembelajaran penemuan dengan prinsip-prinsip dari teori desain instruksional kognitif (D. Handayani et al., 2021; Harianti, 2018). Penerapan model pembelajaran ini mampu menciptakan situasi belajar siswa aktif dan mandiri dalam menyelidiki dan menemukan pengetahuan (Firmansyah, 2013; Sunismi, 2015). Selain itu penerapan model pembelajaran dipadukan dengan kearifan local Bali dapat menanamkan nilai positif pada siswa.

Penanaman nilai atau norma untuk membangun karakter yang sesuai dengan kearifan lokal Bali dapat memberikan kesadaran kepada anak bahwa belajar tidak selalu didasarkan atas skor yang diperoleh sehingga seringkali melakukan upaya yang kurang baik dalam memperoleh hasil belajar (Artawan \& Ardiawan, 2018; Widiasih, 2019). Penanaman nilai atau norma ini dilaksanakan melalui muatan kosep Tri Kaya Parisudha dalam proses pembelajaran. Tri Kaya Parisudha merupakan tiga dasar perilaku individu yang harus disucikan, yaitu pikiran, perkataan, dan perbuatan (Selamet, 2017; Somawati \& Made, 2019). Tri Kaya Parisudha terdiri atas tiga bagian, yaitu Manacika berarti berpikir yang suci atau yang benar, Wacika berarti berkata yang benar, dan Kayika berarti berbuat yang benar (Dewi et al., 2014; Priantini, 2020). Makna berpikir, berkata, dan berbuat yang benar ini adalah selalu mengacu pada pandangan dharma (kebenaran) (Dewi et al., 2014; Somawati \& Made, 2019). Secara teknis, pengembangan ini memberikan keterkaitan konsep Tri Kaya Parisudha, yaitu Manacika, Wacika, dan Kayika dengan keterampilan abad 21 yaitu critical thinking, communication, collaboration, dan creativity yang diimplikasikan dalam rencana pelaksanaan pembelajaran dengan model pembelajaran guided discovery.

Temuan penelitian sebelumnya menyatakan bahwa model pembelajaran guided discovery dapat meningkatkan keaktifan siswa dalam belajar (Alatas \& Sakina, 2019; Sunismi, 2015). Temuan penelitian sebelumnya juga menyatakan bahwa model pembelajaran guided discovery (D. Handayani et al., 2021; Harianti, 2018). Temuan penelitian lainnya juga menyatakan bahwa Tri Kaya Parisudha dapat 
menanamkan nilai karakter pada siswa (Artawan \& Ardiawan, 2018; Widiasih, 2019). Dapat disimpulkan bahwa model pembelajaran guided discovery dengan pendekatan Tri Kaya Parisudha dapat membantu siswa dalam belajar. Belum adanya kajian model pembelajaran guided discovery dengan pendekatan Tri Kaya Parisudha. Tujuan penelitian ini yaitu mengembangkan model guided discovery berorientasi pembelajaran Abad 21 bermuatan Tri Kaya Parisudha. Pengembangan keterampilan abad 21 dan pengamalan konsep Tri Kaya Parisudha dalam proses pembelajaran dengan model guided discovery diharapkan mampu memberikan kajian empiris untuk meningkatkan kualitas proses pembelajaran, kompetensi siswa, dan penguatan pendidikan karakternya.

\section{METODE}

Jenis penelitian ini yaitu pengembangan. Desain pada penelitian ini adalah pengembangan desain dan produk (Design and Development) dengan menggunakan model ADDIE. Model ADDIE ini terdiri lima komponen, yaitu: analisis (analysis), perancangan (design), pengembangan (development), implementasi (implementation), dan evaluasi (evaluation) (Ayu et al., 2015; Wulandari et al., 2020). Subjek penelitian ini adalah 2 orang dosen ahli, yaitu ahli konten dan ahli bahasa; 5 orang guru SD di Kecamatan Buleleng; dan 5 mahasiswa PGSD STAHN Mpu Kuturan Singaraja. Metode yang digunakan untuk mengumpulkan data yaitu observasi, wawancara, dan kuesioner. Instrument yang digunakan untuk mengumpulkan data yaitu kuesioner. Adapun kisi-kisi kuesioner disajikan pada Tabel 1. Sumber data pada penelitian ini terdiri atas data primer dan data sekunder. Data primer berupa hasil kuesioner yang diberikan kepada subjek penelitian dan wawancara dengan guru SD. Data sekunder berupa buku referensi. Data dan teknik pengumpulan data penelitian mencakup 3 dimensi penilaian, yaitu: bahasa dan penulisan; komponenkomponen buku yang baik; dan kebermanfaatan atau aplikasi yang dikumpulkan dengan teknik kuesioner. Teknik analisis data dilaksanakan secara deskriptif kualitatif dan kuantitatif serta mengkonversi hasilnya sesuai kategori PAIT.

Tabel 1. Kisi-Kisi Instrumen Penelitian

\begin{tabular}{|c|c|c|}
\hline No & Jenis Instrumen & Indikator \\
\hline \multirow[t]{3}{*}{1} & Instrumen Ahli Bahasa & 1. Keterbacaan \\
\hline & & 2. Kesesuaian dengan kaidah Bahasa Indonesia yang baik dan benar \\
\hline & & 3. Keseluruhan \\
\hline \multirow[t]{6}{*}{2} & Instrumen Ahli Konten & 1. Legalitas \\
\hline & & 2. Norma \\
\hline & & 3. Materi/Substansi \\
\hline & & 4. Bahasa \\
\hline & & 5. Penyajian \\
\hline & & 6. Keseluruhan \\
\hline \multirow[t]{5}{*}{4} & Instrumen Respon Guru & 1. Tampilan fisik \\
\hline & dan mahasiswa & 2. Bahasa dan Penulisan \\
\hline & & 3. Isi \\
\hline & & 4. Kebermanfaatan \\
\hline & & 5. Keseluruhan \\
\hline
\end{tabular}

\section{HASIL DAN PEMBAHASAN}

Hasil

Model pembelajaran guided discovery adalah siswa dapat menemukan atau menyelidiki suatu konsep dengan bimbingan atau arahan yang diberikan oleh guru sehingga siswa akan lebih mudah dalam menyelesaikan permasalahan yang berhubungan dengan konsep tersebut. Siswa yang menemukan atau menyelidiki sendiri suatu konsep akan lebih mudah di pahami, dimengerti dan mudah diingat. Adapun pengembangan sintaks model pembelajaran yang menjadi dasar implementasi guided discovery bermuatan Tri Kaya Parisudha pada penelitian ini disajikan pada Tabel 2. Tahap implementation dan evaluation dilakukan untuk menunjukkan tingkat validitas pengembangan model guided discovery berorientasi pembelajaran abad 21 bermuatan Tri Kaya Parisudha. Tahap implementation dilaksanakan dengan melakukan uji validasi ahli bahasa dan uji validasi ahli konten. Berdasarkan hasil penilaian yang dilakukan oleh ahli bahasa, dari aspek keterbacaan mendapatkan skor 3,8 sehingga mendapatkan kategori sangat baik. Dari aspek kesesuaian dengan kaidah bahasa Indonesia mendapatkan skor 3,6 sehingga mendapatkan kategori sangat baik. Pada aspek keseluruhan mendapatkan skor 3,73 sehingga 
mendapatkan kategori sangat baik. Berdasarkan hasil penilaian yang dilakukan oleh ahli konten, dari aspek legalitas mendapatkan skor 3,3 sehingga mendapatkan kategori sangat baik. Pada aspek norma 4,00, aspek materi mendapatkan skor 3,57, aspek bahasa 3,33, aspek penyajian mendapatkan skor 3,67, dan aspek keseluruhan mendapatkan nilai 3,55. Berdasarkan hasil penilaian yang diberikan oleh ahli konten dapat disimpulkan bahwa model guided discovery berorientasi pembelajaran abad 21 bermuatan Tri Kaya Parisudha yang dihasilkan pada penelitian ini memperoleh kategori sangat baik. Ini menunjukkan, hasil pengembangan model guided discovery berorientasi pembelajaran abad 21 bermuatan Tri Kaya Parisudha sangat layak untuk digunakan untuk meningkatkan kualitas proses pembelajaran, kompetensi siswa, dan penguatan pendidikan karakter siswa.

Tabel 2. Sintaks Model Pembelajaran Guided Discovery Berorientasi Pembelajaran Abad 21 Bermuatan Tri Kaya Parisudha

\begin{tabular}{|c|c|c|}
\hline Fase & Aktivitas Guru & Aktivitas Siswa \\
\hline $\begin{array}{l}\text { Stimulation } \\
\text { Menciptakan kondisi interaktif } \\
\text { dalam pembelajaran sehingga } \\
\text { siswa untuk lebih aktif dalam } \\
\text { mengeksplorasi materi } \\
\text { (Critical thinking) } \\
\text { (Manacika) }\end{array}$ & $\begin{array}{l}\text { Guru memulai proses pembelajaran } \\
\text { dengan mengajukan beberapa } \\
\text { pertanyaan, menyarankan siswa } \\
\text { membaca buku, dan melaksanakan } \\
\text { kegiatan pembelajaran lainnya } \\
\text { sebagai persiapan penyelesaian } \\
\text { masalah. }\end{array}$ & $\begin{array}{l}\text { - Siswa mencermati } \\
\text { informasi yang } \\
\text { disampaikan guru } \\
\text { - Siswa mencermati sumber } \\
\text { pembelajaran untuk } \\
\text { mempersiapkan } \\
\text { penyelesaian masalah }\end{array}$ \\
\hline $\begin{array}{l}\text { Problem Statement } \\
\text { Mengidentifikasi berbagai } \\
\text { permasalahan kemudian } \\
\text { memilih salah satu } \\
\text { permasalahan utama dan } \\
\text { merumuskan hipotesisnya } \\
\text { (Critical thinking) } \\
(\text { Manacika) }\end{array}$ & $\begin{array}{l}\text { Guru memberikan kesempatan } \\
\text { siswa untuk mengidentifikasi semua } \\
\text { masalah yang terkait dengan materi } \\
\text { pembelajaran. Selanjutnya, salah } \\
\text { satu masalah dipilih dan } \\
\text { dirumuskan dalam bentuk hipotesis } \\
\text { (jawaban sementara untuk } \\
\text { pertanyaan masalah). }\end{array}$ & $\begin{array}{l}\text { - Siswa mengidentifikasi } \\
\text { masalah } \\
\text { - Siswa memilih salah satu } \\
\text { permasalahan } \\
\text { - Siswa merumuskan } \\
\text { hipotesis }\end{array}$ \\
\hline $\begin{array}{l}\text { Data Collection } \\
\text { Mengumpulkan informasi } \\
\text { untuk membuktikan hipotesis } \\
\text { (Critical thinking, } \\
\text { Collaboration) } \\
(\text { Manacika, Kayika) }\end{array}$ & $\begin{array}{l}\text { Guru memberikan kesempatan } \\
\text { kepada siswa untuk mengumpulkan } \\
\text { informasi yang relevan sebanyak } \\
\text { mungkin untuk membuktikan } \\
\text { hipotesis. }\end{array}$ & $\begin{array}{l}\text { Siswa melaksanakan kegiatan } \\
\text { yang relevan seperti membaca } \\
\text { literatur, mengamati objek, } \\
\text { mewawancarai sumber, } \\
\text { melakukan eksperimen untuk } \\
\text { mengumpulkan informasi }\end{array}$ \\
\hline $\begin{array}{l}\text { Data Processing } \\
\text { Pengolahan data yang telah } \\
\text { diperoleh dan menafsirkannya } \\
\text { (Critical thinking, } \\
\text { Collaboration) } \\
(\text { Manacika, Kayika })\end{array}$ & $\begin{array}{l}\text { Guru memberikan petunjuk dalam } \\
\text { mengolah data atau informasi yang } \\
\text { diperoleh siswa melalui wawancara, } \\
\text { observasi, dan sebagainya } \\
\text { kemudian menafsirkannya. }\end{array}$ & $\begin{array}{l}\text { - Siswa mengolah data atau } \\
\text { informasi yang diperoleh } \\
\text { melalui wawancara, } \\
\text { observasi, dan sebagainya. } \\
\text { - Siswa menafsirkan hasil } \\
\text { data yang diperoleh }\end{array}$ \\
\hline $\begin{array}{l}\text { Verification } \\
\text { Menyajikan data yang } \\
\text { diperoleh dan membuktikan } \\
\text { hipotesis } \\
\text { (Critical thinking, } \\
\text { Collaboration, Communication, } \\
\text { Creativity) } \\
\text { (Manacika, Wacika, Kayika) }\end{array}$ & $\begin{array}{l}\text { Guru memberikan kesempatan } \\
\text { siswa untuk melakukan } \\
\text { pemeriksaan terhadap hasil } \\
\text { pengolahan data dan membuktikan } \\
\text { hipotesis }\end{array}$ & $\begin{array}{l}\text { - Siswa menyajikan data } \\
\text { yang diperoleh } \\
\text { - Siswa membuktikan } \\
\text { hipotesis berdasarkan hasil } \\
\text { pengolahan data } \\
\text { - Siswa melaksanakan } \\
\text { diskusi untuk } \\
\text { memverifikasi } \\
\text { penemuannya }\end{array}$ \\
\hline $\begin{array}{l}\text { Generalization } \\
\text { Proses menarik kesimpulan } \\
\text { berdasarkan permasalahan } \\
\text { yang diajukan sebelumnya dan } \\
\text { mempertimbangkan hasil } \\
\text { verifikasi. } \\
\text { (Critical thinking, } \\
\text { Communication, Creativity) } \\
\text { (Manacika, Wacika) }\end{array}$ & $\begin{array}{l}\text { Guru membimbing siswa dalam } \\
\text { menyimpulkan hasil penemuannya }\end{array}$ & $\begin{array}{l}\text { - Siswa mengajukan } \\
\text { kesimpulan berdasarkan } \\
\text { hasil verifikasi (penemuan) } \\
\text { - Siswa memformulasikan } \\
\text { hasil penemuannya sebagai } \\
\text { dasar pemahaman konten } \\
\text { pembelajaran. }\end{array}$ \\
\hline
\end{tabular}


Tahap terakhir desain pengembangan penelitian ini yang menunjukkan validitas hasil penelitian adalah evaluation. Tahap ini dilaksanakan dengan pemberian kuesioner terhadap 5 mahasiswa PGSD STAHN Mpu Kuturan Singaraja dan 5 guru SD di Kecamatan Buleleng untuk memperoleh respons terhadap produk pengembangan yang telah dihasilkan. Berdasarkan hasil respon mahasiswa, dari tampilan fisik mendapatkan skor 3,56 (sangat baik). Aspek bahasa dan penulisan mendapatkan skor 3, 63 (sangat baik). Aspek isi mendapatkan skor 3,38 (sangat baik). Aspek kebermanfaatan mendapatkan skor 3,37 (sangat baik). Aspek keseluruhan mendapatkan skor 3,43 (sangat baik). Berdasarkan hasil respon mahasiswa dapat disimpulkan bahwa model guided discovery berorientasi pembelajaran abad 21 bermuatan Tri Kaya Parisudha yang dihasilkan pada penelitian ini memperoleh kategori sangat baik. Berdasarkan hasil respon guru, dari tampilan fisik mendapatkan skor 3,44 (sangat baik). Aspek bahasa dan penulisan mendapatkan skor 3, 39 (sangat baik). Aspek isi mendapatkan skor 3,28 (sangat baik). Aspek kebermanfaatan mendapatkan skor 3,37 (sangat baik). Aspek keseluruhan mendapatkan skor 3,36 (sangat baik). Berdasarkan hasil respon guru dapat disimpulkan bahwa model guided discovery berorientasi pembelajaran abad 21 bermuatan Tri Kaya Parisudha yang dihasilkan pada penelitian ini memperoleh kategori sangat baik. Berdasarkan hasil respon mahasiswa dan guru SD, pengembangan model guided discovery berorientasi pembelajaran abad 21 bermuatan Tri Kaya Parisudha sangat relevan untuk digunakan dan diterapkan untuk meningkatkan kualitas proses pembelajaran. Hasil uji validitas ahli bahasa dan konten serta respon dari mahasiwa dan guru SD telah menunjukkan bahwa model guided discovery berorientasi pembelajaran abad 21 bermuatan Tri Kaya Parisudha yang dihasilkan pada penelitian ini valid.

\section{Pembahasan}

Peran guru dalam penerapan model guided discovery sesuai dengan karakteristik pada pembelajaran abad 21, yaitu sebagai fasilitator, motivator, dan insipirator (Alatas \& Sakina, 2019; Sukmasari \& Rosana, 2017). Hal ini ditunjukan dengan minat baca yang tinggi, memiliki kemampuan menulis karya ilmiah, memiliki kreativitas dan inovasi dalam menerapkan model-model pembelajaran; dan bertransformasi secara kultural (Dayanti, 2017; Desyandri et al., 2019). Pada sisi lain, karakteristik siswa dalam pembelajaran abad 21, yaitu: berpikir kritis, mampu memecahkan masalah, komunikatif, kreatif, kolaboratif, dan inovatif; memiliki kemampuan dalam literasi digital, media baru, dan ICT; serta memiliki inisiatif, fleksibel, dan adaptif (Alatas \& Sakina, 2019; Ladjar et al., 2018; Prastika et al., 2021). Hal ini sejalan dengan aspek keterampilan 4C, yaitu critical thinking; collaboration; communication; dan creativity serta nilai karakter Tri Kaya Parisudha yaitu Manacika (berpikir yang baik), Wacika (berkata yang baik), dan Kayika (berbuat yang baik) (Artawan \& Ardiawan, 2018; S. L. Handayani \& Amirullah, 2019; Kembara et al., 2018). Kebermanfaatan pengembangan model pembelajaran guided discovery juga sesuai dengan kelebihan model guided discovery yaitu siswa akan lebih aktif dalam kegiatan belajar karena siswa dapat berpikir dan menggunakan kemampuannya untuk menemukan hasil akhir (Indah, 2020; Sukmasari \& Rosana, 2017). Selain itu, siswa memahami benar bahan pembelajaran karena siswa mengalami sendiri proses menemukannya. Model ini dapat melatih siswa untuk lebih banyak belajar sendiri, dapat menanamkan rasa ingin tahu, menimbulkan kerja sama dan interaksi antar siswa (Ardianti et al., 2017; Dayanti, 2017; Desyandri et al., 2019).

Pada sisi lain, pembelajaran abad 21 khususnya di sekolah dasar juga diharapkan mampu menguatkan pendidikan karakter bagi siswa. Pengembangan karakter siswa dalam proses pembelajaran dapat ditekankan melalui dua aspek, yaitu aspek strategi atau model pembelajaran dan aspek konsep keilmuan bidang pelajaran terkait (Agnies zka Bates, 2019; Pane \& Rina Patriana, 2016; Prasetyo et al., 2020). Hal inilah diperlukan salah satu konsep kearifan lokal dalam penerapan pembelajaran abad 21, yakni melalui implementasi konsep Tri Kaya Parisudha yang terdiri atas Manacika, Wacika, dan Kayika (Artawan \& Ardiawan, 2018; Widiasih, 2019). Temuan penelitian sebelumnya menyatakan bahwa model pembelajaran guided discovery dapat memudahkan siswa dalam belajar (Indah, 2020; Restyani, 2018). Temuan penelitian sebelumnya menyatakan bahwa model pembelajaran guided discovery dapat meningkatkan motivasi belajar siswa (Desyandri et al., 2019; Sukmasari \& Rosana, 2017). Temuan penelitian lainnya juga menyatakan bahwa Tri Kaya Parisudha dapat membangun karakter siswa (Priantini, 2020; Selamet, 2017; Somawati \& Made, 2019). Dapat disimpulkan bahwa model pembelajaran guided discovery dengan muatan Tri Kaya Parisudha dapat membantu siswa dalam belajar dan membangun karakter siswa. Berdasarkan hasil temuan tersebut, maka pengembangan model guided discovery learning mampu mengembangkan keterampilan siswa dalam berpikir kritis (critical thinking) dilandasi fikiran baik (manacika), berkomunikasi (communication) dilandasi perkataan baik (wacika), bekerja sama (collaboration) dan berkreasi (creativity) yang dilandasi perbuatan baik (kayika) sesuai dengan orientasi pembelajaran abad 21 disertai muatan Tri Kaya Parisudha. Penelitian ini juga didukung 
oleh penelitian yang dilakukan Robi (2018) yang mengembangkan perangkat pembelajaran guided discovery learning untuk menganalisis keterampilan berpikir kritis mahasiswa. Hasil penelitiannya pun menyatakan bahwa pengembangan perangkat valid dan layak untuk meningkatkan keterampilan berpikir kritis. Sedangkan keterampilan berpikir kritis tersebut merupakan salah satu komponen dari keterampilan abad 21. Oleh karena itu, diyakini dengan pengembangan guided discovery learning dapat mengembanglan keterampilan 4c siswa, sesuai dengan pembelajaran abad 21. Hanya untuk menciptakan generasi cerdas dan berkarakter perlu dikolaborasikan dengan kearifan lokal yaitu muatan Tri Kaya Parisudha.

\section{SIMPULAN}

Pengembangan model guided discovery learning berorientasi pembelajaran abad 21 bermuatan Tri Kaya Parisudha mendapatkan kualifikasi sangat baik dari para ahli, guru dan siswa. Dapat disimpulkan bahwa model guided discovery learning berorientasi pembelajaran abad 21 bermuatan Tri Kaya Parisudha layak diterapkan dalam pembelajaran. Sintaks pembelajaran ini yang nantinya dapat digunakan oleh guru saat mengajar siswa agar nantinya mampu meningkatkan keterampilan 4C dan disertai dengan manacika, kayika, dan wacika, sesuai bagian Tri Kaya Parisudha sehingga menciptakan generasi yang cerdas dan berkarakter.

\section{DAFTAR PUSTAKA}

Agnies zka Bates. (2019). Character education and the 'priority of recognition. Cambrid Ge Journal of Educatio N, 49(6), 695-710. https://doi.org/10.1080/0305764X.2019.1590529.

Alatas, F., \& Sakina, W. H. (2019). Guided Discovery Berbantuan Virtual Lab untuk Meningkatkan Keterampilan Proses Sains dan Sikap Ilmiah. JIPVA (Jurnal Pendidikan IPA Veteran), 3(2), 138148. https://doi.org/10.31331/jipva.v3i2.864.

Alshammari, M. T. (2020). Evaluation of gamification in e-learning systems for elementary school students. TEM Journal, 9(2). https://doi.org/10.18421/TEM92-51.

Amin, I., Yousaf, A., Walia, S., \& Bashir, M. (2021). What Shapes E-Learning Effectiveness among Tourism Education Students? An Empirical Assessment during COVID19. Journal of Hospitality, Leisure, Sport and Tourism Education, $x x x(x x x x), 100337$. https://doi.org/10.1016/j.jhlste.2021.100337.

Andrian, \& Rusman. (2019). Implementasi pembelajaran abad 21 dalam kurikulum 2013. Jurnal Penelitian Ilmu Pendidikan, 12(1). https://doi.org/10.21831/jpipfip.v12i1.20116. 14-23.

Ardianti, S. D., Pratiwi, I. A., \& Kanzunnudin, M. (2017). Implementasi Project Based Learning (PjBL) Berpendekatan Science Edutainment Terhadap Kreativitas Peserta Didik. Refleksi Edukatika: Jurnal Ilmiah Kependidikan, 7(2), 145-150. https://doi.org/10.24176/re.v7i2.1225.

Artawan, K. N., \& Ardiawan, I. K. N. (2018). Pembelajaran quantum Teaching berbasis Tri Kaya Parisudha. Edudikara: Jurnal Pendidikan Dan Pembelajaran, 3(2), 201-212. https://doi.org/10.32585/edudikara.v3i2.100.

Arum, R. A. S., \& Yuanta, F. (2019). Pengaruh Media Pop-Up Book Terhadap Hasil Belajar Siswa Sekolah Dasar Tema Indahnya Keragaman Di Negeriku. Prosiding Seminar Nasional Cendekiawan, 2. https://doi.org/10.25105/semnas.v0i0.5875.

Ayu, G., Mega, M., Sudhita, I. W. R., \& Suwatra, I. I. W. (2015). Pengembangan Multimedia Pembelajaran Interaktif Agama Hindu Dengan Model ADDIE untuk Siswa Kelas VIII SMP. Jurnal Eductech Undiksha, 3(1), 1-11. https://doi.org/10.23887/jeu.v3i1.5869.

Azrai, E. P., Evriyani, D., \& Prastya, A. R. (2016). Hubungan tingkat kecemasan siswa dalam menghadapi tes dengan tingkat motivasi belajar biologi pada siswa kelas X MIA SMA Negeri 21 Jakarta. Biosfer: Jurnal Pendidikan Biologi (Biosferjpb), 9(1), 47-54. https://doi.org/10.21009/biosferjpb.9-1.8.

Baka, T. ., Laksana, D. N. ., \& Dhiu, K. . (2018). Konten dan Konteks Budaya Lokal Ngada sebagai Bahan Ajar Tematik di Sekolah Dasar. Journal of Education Technology, 2(2), 46-55. https://doi.org/10.23887/jet.v2i2.16181.

Breinholt, A., \& Holm, A. (2020). Heterogeneous effects of less educated mothers' further education during early childhood on children's educational performance in adolescence. Research in Social Stratification and Mobility, 68. https://doi.org/10.1016/j.rssm.2020.100506.

Dayanti, A. D. (2017). Pengembangan Sikap Toleran Terhadap Perbedaan Pendapat Siswa Melalui Discovery Learning Dalam Pembelajaran IPS (Penelitian Tindakan Kelas Terhadap Siswa Kelas VII-C SMP Negeri 44 Bandung). International Journal Pedagogy of Social Studies, 1(1), 60. https://doi.org/10.17509/ijposs.v1i1.2084.

Desyandri, D., Muhammadi, M., Mansurdin, M., \& Fahmi, R. (2019). Development of integrated thematic 
teaching material used discovery learning model in grade $\mathrm{V}$ elementary school. Jurnal Konseling Dan Pendidikan, 7(1), 16. https://doi.org/10.29210/129400.

Dewi, N. K. C., Sedanayasa, G., \& Sulastri, M. (2014). Pengaruh Moidel Pembelajaran Numbered Head Together Berlandasakan Tri Kaya Parisudha Terhadap Hasil Belajar IPA Siswa Kelas V. Mimbar Pgsd Universitas Pendidikan Ganesha, 2(1). https://doi.org/10.23887/jjpgsd.v2i1.4144.

Firmansyah, D. (2013). Strategi Pembelajaran Dan Minat Belajar Terhadap Hasil Belajar Matematika. Jurnal Teknologi Pendidikan (JTP), 6(2), 34-44. https://doi.org/10.24114/jtp.v6i2.4996.

Fisnani, Y., Utanto, Y., \& Ahmadi, F. (2020). The Development of E-Module for Batik Local Content in Pekalongan Elementary School. Innovative Journal of Curriculum and Educational Technology, 9(1), 40-47. https://doi.org/10.15294/IJCET.V9I1.35592.

Handayani, D., Elvinawati, E., Isnaeni, I., \& Alperi, M. (2021). Development Of Guided Discovery Based Electronic Module For Chemical Lessons In Redox Reaction Materials. International Journal of Interactive Mobile Technologies (IJIM), 15(07), 94. https://doi.org/10.3991/ijim.v15i07.21559.

Handayani, S. L., \& Amirullah, G. (2019). Meningkatkan Pemahaman Guru Sekolah Dasar Melalui Pelatihan Penyusunan Rencana Pelaksanaan Pembelajaran Berbasis Literasi, 4C, PPK dan HOTS. Jurnal SOLMA, 8(1), 14-23. https://doi.org/10.29405/solma.v8i1.2949.

Harianti, F. (2018). Pengaruh Model Pembelajaran Guided Discovery Learning terhadap Kemampuan Pemahaman dan Hasil Belajar Siswa Materi Operasi Aljabar Kelas VII SMP. MUST: Journal of Mathematics Education, Science and Technology, 3(1), 82-91. https://doi.org/10.30651/must.v3i1.1611.

Hidayat, W., \& Sariningsih, R. (2018). Kemampuan Pemecahan Masalah Matematis dan Adversity Quotient Siswa SMP Melalui Pembelajaran Open Ended. Jurnal JNPM (Jurnal Nasional Pendidikan Matematika), 2(1), 109-118. https://doi.org/10.1016/S0962-8479(96)90008-8.

Huang, S. Y., Kuo, Y. H., \& Chen, H. C. (2020). Applying digital escape rooms infused with science teaching in elementary school: Learning performance, learning motivation, and problem-solving ability. Thinking Skills and Creativity, 37(129), 100681. https://doi.org/10.1016/j.tsc.2020.100681.

Hutauruk, A., \& Sidabutar, R. (2020). Kendala pembelajaran daring selama masa pandemi di kalangan mahasiswa pendidikan matematika: Kajian kualiatatif deskriptif. Journal of Mathematics Education and Applied, 02(01), 45-51. https://doi.org/10.36655/sepren.v2i1.364.

Indah, P. (2020). Development of HOTS (High Order Thinking Skill) Oriented Learning Through Discovery Learning Model to Increase The Critical Thinking Skill of High School Students. International Journal of Chemistry Education Research, 3(3). https://doi.org/10.20885/ijcer.vol4.iss1.art4.

Kembara, Rozak, \& Hadian. (2018). Research-based Lectures to Improve Students' 4C (Communication, Collaboration, Critical Thinking, and Creativity) Skills. Proceedings of the Second Conference on Language, Literature, Education, and Culture (ICOLLITE), 1(1). https://doi.org/10.2991/icollite18.2019.50, . 20019.11.

Ladjar, M. A. B., Juliantine, T., \& Mulyana. (2018). Pengaruh Model Problem-Based Learning dan Discovery Learning serta Kecerdasan Intelektual terhadap Berpikir Kreatif. Jurnal Pendidikan Jasmani Dan Olahraga, 3(1). https://doi.org/10.17509/jpjo.v3i1.9837.

Lubis, A. (2018). Integrasi Tik Dalam Pengajaran Bahasa Inggris Di Indonesia Abad Ke-21: Mitos Dan Realita. Cakrawala Pendidikan, 37(1), 11-24.

Mitchell, C., Del Fabbro, L., \& Shaw, J. (2017). The acculturation, language and learning experiences of international nursing students: Implications for nursing education. Nurse Education Today, 56, 16-22. https://doi.org/10.1016/j.nedt.2017.05.019.

Mufaziah, E., \& Fauziah, P. (2020). Kendala Orang Tua dalam Mendidik Anak Usia Dini pada Saat Pandemi Covid 19. Jurnal Obsesi, 5(2). https://doi.org/10.31004/obsesi.v5i2.746.

Muflih, S., Abuhammad, S., Al-Azzam, S., Alzoubi, K. H., Muflih, M., \& Karasneh, R. (2021). Online learning for undergraduate health professional education during COVID-19: Jordanian medical students' attitudes and perceptions. Heliyon, 7(9), e08031. https://doi.org/10.1016/j.heliyon.2021.e08031.

Mustakim, M. (2020). Efektivitas Pembelajaran Daring Menggunakan Media Online Selama Pandemi Covid-19 Pada Mata Pelajaran Matematika. Al Asma: Journal of Islamic Education, 2(1), 1-12. https://doi.org/10.24252/asma.v2i1.13646.

Pambudi, B., Efendi, R. B., Novianti, L. A., Novitasari, D., \& Ngazizah, N. (2019). Pengembangan Alat Peraga IPA dari Barang Bekas untuk Meningkatkan Motivasi Belajar dan Pemahaman Siswa Sekolah Dasar. Indonesian Journal of Primary Education, 2(2), 28. https://doi.org/10.17509/ijpe.v2i2.15097.

Pane, M. M., \& Rina Patriana. (2016). The Significance of Environmental Contents in Character Education for Quality of Life. Procedia - Social and Behavioral Sciences, 222, 244-252. https://doi.org/10.1016/j.sbspro.2016.05.153. 
Partovi, T., \& Razavi, M. R. (2019). The effect of game-based learning on academic achievement motivation of elementary school students. Learning and Motivation, 68. https://doi.org/10.1016/j.lmot.2019.101592.

Plenty, S., Magnusson, C., \& Låftman, S. B. (2021). Internalising and externalising problems during adolescence and the subsequent likelihood of being Not in Employment, Education or Training (NEET) among males and females: The mediating role of school performance. SSM - Population Health, 15. https://doi.org/10.1016/j.ssmph.2021.100873.

Prasetyo, G., Hidayatullah, M. F., Akhyar, M., Wiranto, \& Perdana, R. (2020). Strengthening Students' Character Through Multimedia Learning In Primary Schools Education: Systematic LiteraturPrasetyo, G., Hidayatullah, M. F., Akhyar, M., Wiranto, \& Perdana, R. (2020). Strengthening Students' Character Through Multimedia Learning In . Humanities \& Social Sciences Reviews, 8(3), 268-277. https://doi.org/10.18510/hssr.2020.8328.

Prastika, V. Y. A., Riyadi, R., \& Siswanto, S. (2021). Discovery And Core Learning Model Toward Creative Thinking Viewed From Logical Mathematical Intelligence. Jurnal Aksioma, 10(1). https://doi.org/10.24127/ajpm.v10i1.3429.

Pratama, F. I. P., Kristiyanto, A., \& Widyastono, H. (2021). Character Values of Third Grade Slow Learner in Character Education at the Inclusive Elementary School. JPI, 10(2), 345-352. https://doi.org/10.23887/jpi-undiksha.v10i2.28838.

Priantini, D. A. (2020). The Development Of Teaching Video Media Based On Tri Kaya Parisudha In Educational Psychology Courses. Journal of Education Technology, 4(4). https://doi.org/10.23887/jet.v4i4.29608.

Restyani, N. K. N. (2018). Pengaruh Model Pembelajaran Discovery Inquiry Berbasis Portofolio Terhadap Kompetensi Pengetahuan IPA. Jurnal Penelitian Dan Pengembangan Pendidikan, 2(2), 168. https://doi.org/10.23887/jppp.v2i2.15399.

Rigianti, H. A. (2020). Kendala Pembelajaran Daring Guru Sekolah Dasar di Kabupaten Banjarnegara. Orphanet Journal of Rare Diseases, 21(1), 1-9. https://doi.org/10.31316/esjurnal.v7i2.768.

Royanto, L. R. (2012). The Effect of An Intervention Program based on Scaffolding to Improve Metacognitive Strategies in Reading: A Study of Year 3 Elementary School Students in Jakarta. Procedia - Social and Behavioral Sciences, 69. https://doi.org/10.1016/j.sbspro.2012.12.105.

Selamet, N. W. (2017). Pengaruh Model Pembelajaran Numbered Head Together Berbasis Tri Kaya Parisudha Terhadap Hasil Belajar IPS Siswa Kelas IV". E- Journal PGSD Universitas Pendidikan Ganesha. MIMBAR PGSD Undiksha, 5(2), 1-11. https://doi.org/10.23887/jjpgsd.v5i2.10768.

Simatupang, H., Purnama, D., \& Simatupang, Z. (2020). The Development of Best Practice Handbook Learning Strategy Based on Flip Book to Support Blended Learning Processes. Journal of Physics: Conference Series, 1462(1). https://doi.org/10.1088/1742-6596/1462/1/012014.

Somawati, A. V., \& Made, Y. A. D. N. (2019). Implementasi Ajaran Tri Kaya Parisudha Dalam Membangun Karakter Generasi Muda Hindu Di Era Digital. Jurnal Pasupati, 6(1). https://doi.org/10.37428/pspt.v6i1.135.

Soyadı, Y., \& Birgili, B. (2015). Creative and Critical Thinking Skills in Problem-based Learning Environments. Journal of Gifted Education and Creativity, 2(2), 71-71. https://doi.org/10.18200/jgedc.2015214253.

Sujana, I. W. C. (2019). Fungsi Dan Tujuan Pendidikan Indonesia. Adi Widya: Jurnal Pendidikan Dasar, 4(1), 29. https://doi.org/10.25078/aw.v4i1.927.

Sukmasari, V. P., \& Rosana, D. (2017). Pengembangan penilaian proyek pembelajaran IPA berbasis discovery learning untuk mengukur keterampilan pemecahan masalah. Jurnal Inovasi Pendidikan IPA, 3(1), 101-110. https://doi.org/10.21831/jipi.v3i1.10468.

Sunismi. (2015). Developing Guided Discovery Learning Materials Using Mathematics Mobile Learning Application As An Alternative Media For The Students Calculus II. Cakrawala Pendidikan, 34(5). https://doi.org/10.21831/cp.v3i3.7340.

Suwana, I. G. G., Artini, L. P., \& Piscayanti, K. S. (2013). The use of R.A.P. paraphrasing strategy to improve students' reading comprehension at class X.A3 in SMKN 2 Singaraja in academic year 2013/2014. Jurnal Pendidikan Bahasa Inggris Undiksha, 1(1). https://doi.org/10.23887/jpbi.v1i1.3859.

Tajvidi, M., Ghiyasvandian, S., \& Salsali, M. (2014). Probing concept of critical thinking in nursing education in Iran: A concept analysis. Asian Nursing Research, 8(2), 158-164. https: //doi.org/10.1016/j.anr.2014.02.005.

Troussas, C., Krouska, A., \& Sgouropoulou, C. (2020). Collaboration and fuzzy-modeled personalization for mobile game-based learning in higher education. Computers \& Education, 144. https://doi.org/10.1016/j.compedu.2019.103698.

Udo, M. (2011). Effect of Guided-Discovery, Student- Centred Demonstration and the Expository 
Instructional Strategies on Students' Performance in Chemistry. African Research Review. https: //doi.org/10.4314/afrrev.v4i4.69237.

Widiasih, L. S. (2019). Pengaruh Model Pembelajaran SFAE Berbasis Tri Kaya Parisudha terhadap Hasil Belajar Matematika Siswa. Jurnal Ilmiah Sekolah Dasar, 3(2). https://doi.org/10.23887/jisd.v3i2.17758.

Wulandari, Sudatha, \& Simamora. (2020). Pengembangan Pembelajaran Blended Pada Mata Kuliah Ahara Yoga Semester II di IHDN Denpasar. Jurnal Edutech Undiksha, 8(1), 1-15. https://doi.org/10.23887/jeu.v8i1.26459. 